\title{
ANALISIS PENGARUH KOMPETENSI DOSEN TERHADAP PREFERENSI MAHASISWA PADA PROFESI AKUNTAN (STUDI KASUS PADA PTS DI SURAKARTA)
}

\author{
HESTIN MUTMAINAH ${ }^{1)}$, ROSITA ${ }^{2)}$ \\ ${ }^{1}$ Manajemen, STIE Surakarta \\ email: hestin.suryoadi@yahoo.com \\ ${ }^{2}$ Akuntansi, STIE Surakarta \\ email: rositasetiawan@gmail.com
}

\begin{abstract}
This study aims to determine the effect of capabilities of lecturers (teachers) that can affect student preferences in the profession as an accountant. Benefits of the research was to determine the factors of capabilities that can make the students make the selection of the accounting profession. Factors capability in terms of the competence of lecturers (

the questionnaire can be processed. Testing the validity, reliability and classical assumption produce reliable data for use in the research model. The model was tested using multiple regression techniques (multiple regresion).

The results of the research that is of no significance of factors of capability of lecturers consisting of pedagogical competence, personal competence, social competence and professional competence of the students choose the profession as an accountant. It can be said that the great competence of lecturers can not lead students to choose accounting profession.

As a research suggestion would be better if there is a variable in the factor of competence with a preference in the selection of the profession by students.

teachers) under Law No. 14 of 2005 which is pedagogical, personal competence, social competence and professional competence.

This study collected data relating to the object to be used as a sample that is data on PTS Surakarta students who take the program S1 Accounting. Observation and questionnaires conducted with 100 questionnaires with a return rate of $100 \%$ and all the results of
\end{abstract}

Keywords: capability, lecturers, preference, profession, accountants

\section{PENDAHULUAN}

Profesi akuntan terutama Kantor Akuntan Publik di Indonesia menurut data yang terdaftar sebagai auditor bank di Otoritas Jasa Keuangan (OJK) sampai dengan September 2014 adalah 197 KAP. Sedangkan menurut data yang diambil dari Badan Pengawas Pasar Modal (Bapepam), daftar seluruh akuntan publik adalah 729 akuntan yang aktif hanya 459, yang tidak aktif sementara 112, yang tidak aktif tetap 158 akuntan. KAP yang ada di Bursa Efek Indonesia adaah $182 \mathrm{KAP}$.

Jumlah penduduk 248,8 juta pada akhir tahun 2013 yang diperoleh dari data Badan Statistik. Sehingga jumlah akuntan publik yang ada di Indonesia maka hanya memiliki perbandingan 1 akuntan dari 341.289 penduduk Indonesia. Bisa dikatakan bahwa sedikit sekali minat penduduk Indonesia pada profesi Akuntan

Oleh sebab itu sangatlah penting kita menilai peran dunia pendidikan di Indonesia dalam menghasilkan Akuntan Profesional. Hal ini dapat didukung dari penelitian yang dilakukan oleh Samsuddina,etc (2015) di Malaysia yang menyatakan bahwa dosen merupakan memiliki peran dalam menciptakan kesadaran tentang pendidikan professional akuntansi di kalangan mahasiswa. Selain ekstrinsik dan motivasi intrinsik, kesiapan merupakan faktor penting untuk mempengaruhi keputusan mahasiswa dalam mengejar pendidikan professional akuntansi.

Oleh Kutluka,etc (2015) pada penelitiannya yang bertujuan untuk mendeteksi teknik mengajar lebih baik dalam pelajaran akuntansi yang berbeda dan alasan utama mempelajari pelajaran akuntansi. Kesimpulan dari penelitian yang dilakukan yaitu menunjukkan bahwa 
sebagian besar dari mahasiswa mempelajari pelajaran akuntansi hanya sebelum ujian, hal ini dipenaguruhi oleh karakteristik dosen yang mengajar baik dari bidang yang diajarkan, persiapan yang baik dan memiliki kemampuan utunk dapat menjawab.

Berdasarkan fenomena dan penelitian yang pernah dilakukan di atas maka peneliti menghasilkan rumusan masalah yaitu bagaimana kapabilitas pengajar (dosen) dalam bentuk kompetensi sebagai pengajar dapat mempengaruhi preferensi mahasiswa pada pemilihan profesi sebagai akuntan akuntan?

\section{KAJIAN LITERATUR DAN PEGEMBANGAN HIPOTESIS (JIKA ADA) Dosen}

Dosen menurut Undang-Undang Guru dan Dosen yaitu UU no 14 tahun 2005 (Bab I pasal 1) adalah pendidik profesional dan ilmuwan dengan tugas utama mentransformasikan, mengembangkan, dan menyebarluaskan ilmu pengetahuan, teknologi, dan seni melalui pendidikan, penelitian, dan pengabdian kepada masyarakat secara professional.

Professional sebagai pendidik adalah memiliki komptenesi yang terdiri dari kompetensi pedagogic, kompetensi kepribadian, kompetensi social dan kompetensi professional.

\section{Profesi Akuntan}

Profesi merupakan jabatan dimana orang yang menyandangnya memiliki pengetahuan khusus yang diperoleh melalui trainning maupun pengalaman lain atau keduanya, sehingga dapat melayani orang lain sesuai bidangnya disertai disiplin etika yang dikembangkan dan diterapkan oleh keompok anggota profesi tersebut.

Menurut Hendri (2014) pengalaman profesi yang relevan dapat mempengaruhi sikap etis apabila pengalaman tersebut meninggalkan kesan yang kuat. Kesan positif yang kuat dapat terbentuk apabila pengalaman profesi tersebut terjadi dalam situasi yang melibatkan faktor emosional.

Profesi akuntan terdiri dari akuntan publik, akuntan pemerintah, akuntan manajemen dan akuntan pendidik.

\section{Penelitian Terdahulu}

Penelitian yang dilakukan oleh Lydia Setyawardani (2009) menghasilkan kesimpulan tentang mahasiswa senior dan junior program studi S1 yang memiliki perbedaaan persepsi tentang profesi akuntan.

Hasil penelitian Kurnia (2009) menyatakan bahwa mahasiswa memiliki persepsi yang sama dengan staf akuntan publik terhadap keahlian yang harus dimiliki agar mencapai kesuksesan karir di KAP.

Penelitian Sutrisno dan Ilmiani (2013) menghasilkan pernyataan bahwa mahasiswa program studi akuntansi memiliki keinginan untuk menjadi auditor namun masih ragu menjadi seorang auditor. Hal ini bukan karena faktor pengetahuan dan akses namun faktor aplikasi ilmu, tantangan, salary, dan prestise.

Oding Supriadi (2011) menyatakan bahwa kapabilitas manajerial dapat digunakan untuk mengestimasi, memprediksi atau menjelaskan kualitas pembelajaran akuntansi di sekolah dan kapabilitas para manajer pendidikan mempengaruhi kualitas pembelajaran akuntansi secara signifikan.

Penelitian Wirianata dan Harahap (2007) menghasilkan kesimpulan dalam penelitiannya adalah bahwa dosen S1 akuntansi masih menganggap profesi akuntan publik lebih positif daripada mahasiswa S1 akuntansi.

Mas Ervina Samsuddina, Noor Sufiawati Khairania, Emelin Abdul Wahida dan Fazrul Hanim Abd Sataa (2015) melakukan penelitian yang bertujuan untuk menyelidiki kesadaran, motivasi dan kesiapan untuk pendidikan akuntansi profesional di kalangan mahasiswa akuntansi di Malaysia. Studi kasus ini berfokus pada kesadaran, motivasi dan kesiapan untuk pendidikan akuntansi profesional di kalangan mahasiswa akuntansi di UiTM Johor. Bukti kasus 
menunjukkan pentingnya program pemasaran, rekan-rekan selama pelatihan praktis, dan dosen dalam menciptakan kesadaran tentang pendidikan akuntansi profesional di kalangan mahasiswa.

Penelitian oleh Filiz Angay Kutluka, Adnan Donmezb, dan Mustafa Gülmezc (2015) bertujuan untuk menentukan pendapat mahasiswa tentang teknik mengajar di berbagai jenis pelajaran akuntansi. Teknik pengajaran meliputi perangkat yang digunakan, jenis pengajaran dan karakteristik dosen akuntansi.

\section{METODE PENELITIAN}

Penelitian ini dilakukan pada mahasiswa program studi S1 akuntansi di Perguruan Tinggi Swasta yang ada di wilayah Surakarta sebagai responden dari kuisioner yang dibagikan.

\section{Variabel Operasional}

Dalam penelitian ini variabel independen yang digunakan adalah kompetensi pedagogik, kompetensi kepribadian, kompetensi profesional dan kompetensi sosial. Sedangkan preferensi sebagai akuntan menjadi variabel dependen.

\section{Model Yang Digunakan}

Dalam penelitian ini menggunakan metode statistik untuk menguji hipotesis yang dibuktikan dengan menggunakan regresi berganda (multiple regression). Model persamaan yang digunakan adalah sebagai berikut :

$Y=a_{1}+\beta_{1} X_{1}+\beta_{2} X_{2}+\beta_{3} X_{3}+\beta_{4} X_{4}+\varepsilon$

Keterangan :

Y : Preferensi Profesi Akuntan

$\mathrm{X}_{1}$ : Kompetensi Pedagogik

$\mathrm{X}_{2}$ : Kompetensi Kepribadian

$\mathrm{X}_{3}$ : Kompetensi Profesional

$\mathrm{X}_{4}$ : Kompetensi Sosial

$\beta$ : Koefisien Regresi

$\varepsilon$ : Error

\section{HASIL DAN PEMBAHASAN}

Hasil

Data Responden

Responden yang digunakan dalam penelitian ini adalah mahasiswa jurusan akuntansi pada perguruan tinggi swasta di Surakarta. Data yang digunakan dengan cara menggunakan kuisioner yang dibagikan oleh peneliti kepada 100 mahasiswa yang mewakili PTS di wilayah Surakarta. Pemilihan responden berdasarkan random sampling, dengan pemenuhan criteria yang diinginkan oleh peneliti. Kriteria yang digunakan dalam penelitian ini adalah :

a. Mahasiswa jurusan akuntansi (S1)

b. Mahasiswa semester yang sedang atau sudah menempuh semester 4

Dari 100 kuisioner yang dibagikan semua kembali karena responden dibagi kuisioner yang kemudian langsung ditarik kembali. Jadi pengembalian kuisioner $100 \%$. berikut :

Dari hasil pengumpulan data kusioner maka dapat digambarkan pada table sebagai

Tabel 1. Identitas Responden Berdasarkan Jenis Kelamin

\begin{tabular}{|c|c|c|}
\hline $\begin{array}{c}\text { Jenis } \\
\text { Kelamin }\end{array}$ & $\begin{array}{c}\text { JUMLAH } \\
\text { (Orang) }\end{array}$ & $\begin{array}{c}\text { PROSENTAS } \\
\text { E } \\
(\%)\end{array}$ \\
\hline - Laki-laki & 34 & $34 \%$ \\
-Perempuan & 66 & $66 \%$ \\
\hline Jumlah & 100 & $100 \%$ \\
\hline
\end{tabular}

Sumber : Data yang diolah, 2016 
Tabel 2. Identitas Responden Berdasarkan Semester

\begin{tabular}{|l|c|c|}
\hline $\begin{array}{c}\text { Semeste } \\
\mathrm{r}\end{array}$ & $\begin{array}{c}\text { JUMLAH } \\
\text { (Orang) }\end{array}$ & $\begin{array}{c}\text { PROSENTAS } \\
\mathrm{E} \\
(\%)\end{array}$ \\
\hline - IV & 89 & $89 \%$ \\
- > IV & 11 & $11 \%$ \\
\hline Jumlah & 100 & $100 \%$ \\
\hline
\end{tabular}

Sumber : Data yang diolah, 2016

\section{Uji Instrument Penelitian}

\section{Uji Validitas}

Uji ini dilakukan sebelum kuisioner dapat digunakan agar menjamin bahwa kuisioner yang mampu mengukur apa yang seharusnya diukur. Hasil dari uji validitas dapat disajikan pada table berikut ini :

Table 3. Hasil Uji Validitas

\begin{tabular}{|c|c|c|c|c|}
\hline Varia-bel & $\begin{array}{c}\text { Indika } \\
\text { tor }\end{array}$ & $\begin{array}{c}\text { Sig. } \\
(2- \\
\text { tailed })\end{array}$ & $\begin{array}{c}\text { Sig. } \\
\text { Bartlett } \\
\text { test }\end{array}$ & $\begin{array}{c}\text { Keteran } \\
\text { gan }\end{array}$ \\
\hline Pedagogik & $\mathrm{X} 11$ & 0,000 & 0,05 & Valid \\
\cline { 2 - 5 } & $\mathrm{X} 12$ & 0,000 & 0,05 & Valid \\
\cline { 2 - 5 } & $\mathrm{X} 13$ & 0,000 & 0,05 & Valid \\
\cline { 2 - 5 } & $\mathrm{X} 14$ & 0,000 & 0,05 & Valid \\
\hline Kepribadian & $\mathrm{X} 21$ & 0,000 & 0,05 & Valid \\
\cline { 2 - 5 } & $\mathrm{X} 22$ & 0,000 & 0,05 & Valid \\
\cline { 2 - 5 } & $\mathrm{X} 23$ & 0,000 & 0,05 & Valid \\
\cline { 2 - 5 } & $\mathrm{X} 24$ & 0,000 & 0,05 & Valid \\
\hline Profesional & $\mathrm{X} 31$ & 0,000 & 0,05 & Valid \\
\cline { 2 - 5 } & $\mathrm{X} 32$ & 0,000 & 0,05 & Valid \\
\cline { 2 - 5 } & $\mathrm{X} 33$ & 0,000 & 0,05 & Valid \\
\cline { 2 - 5 } & $\mathrm{X} 34$ & 0,000 & 0,05 & Valid \\
\hline Sosial & $\mathrm{X} 41$ & 0,000 & 0,05 & Valid \\
\cline { 2 - 5 } & $\mathrm{X} 42$ & 0,000 & 0,05 & Valid \\
\cline { 2 - 5 } & $\mathrm{X} 43$ & 0,000 & 0,05 & Valid \\
\hline Profesi & $\mathrm{Y} 1$ & 0,000 & 0,05 & Valid \\
\cline { 2 - 5 } Akuntan & $\mathrm{Y} 2$ & 0,000 & 0,05 & Valid \\
\cline { 2 - 5 } & $\mathrm{Y} 3$ & 0,000 & 0,05 & Valid \\
\cline { 2 - 5 } & $\mathrm{Y} 4$ & 0,000 & 0,05 & Valid \\
\hline
\end{tabular}

Sumber : Data yang diolah, 2016

Dari hasil uji tersbut karena signifikansi yang ditunjukkan kurang dari 0,05 maka dikatakan bahwa data tersebut valid. Sehingga pertanyaan-pertanyaan yang ada pada kuisioner memang mewakili apa yang akan diukur.

\section{Uji Reliabilitas}

Untuk dapat mengetahui konsistensi atas jawaban dari kusioner maka diuji dengan menggunakan uji reliabilitas. Sehingga jika responden diberi pertanyaan yang sama secara berulangkali dari waktu ke waktu akan memiliki jawaban yang sama. Instrumen akan dikatan reliabel pada saat menghasilkan Cronbach Alpha $(\alpha)$ lebih dari 0,60 menurut 
Nunnally, 1967 (Ghozali, 2005). Hasil reliabilitas dari penelitian ini disajikan dalam table data sebagai berikut :

Tabel 4. Hasil Uji Reliabilitas

\begin{tabular}{|l|c|c|c|}
\hline \multicolumn{1}{|c|}{ Variabel } & $\begin{array}{c}\text { Hasil } \\
\text { Cronbach's } \\
\text { Alpha }\end{array}$ & Standar Reliabilitas & Keterangan \\
\hline Pedagogik & $0,780>0,60$ & 0,70 & Reliabel \\
\hline Kepribadian & $0,788>0,60$ & 0,70 & Reliabel \\
\hline Profesional & $0,780>0,60$ & 0,70 & Reliabel \\
\hline Sosial & $0,747>0,60$ & 0,70 & Reliabel \\
\hline $\begin{array}{l}\text { Preferensi Profesi } \\
\text { Akuntan }\end{array}$ & $0,778>0,60$ & 0,70 & Reliabel \\
\hline
\end{tabular}

Sumber : Data yang diolah, 2016

\section{Uji Asumsi Klasik}

\section{Uji Multikolonieritas}

Uji ini untuk menguji adanya korelasi di antar variable pada model yang digunakan (Ghozali,2011). Hasil dari uji multikolonieritas dapat dikatakan tidak terjadi multikolonieritas jika Tolerance $\geq 0.10$ atau niai VIF $\leq 10$. Hasil uji multikolonieritas dari penelitian ini adalah sebagai berikut :

Tabel 5. Hasil Uji Multikolonieritas

\begin{tabular}{|l|l|l|l|l|}
\hline No & Variabel & VIF & $\alpha$ & Keterangan \\
\hline 1 & Pedagogik & 1,092 & 10 & Tidak Terjadi Multikolonieritas \\
\hline 2 & Kepribadian & 1,157 & 10 & Tidak Terjadi Multikolonieritas \\
\hline 3 & Profesional & 1,131 & 10 & Tidak Terjadi Multikolonieritas \\
\hline 4 & Sosial & 1,079 & 10 & Tidak Terjadi Multikolonieritas \\
\hline
\end{tabular}

Sumber : Data yang diolah, 2016

\section{Uji Heteroskedastisitas}

Uji heteroskedastisitas bertujuan untuk menguji apakah dalam model regresi terjadi ketidaksamaan variance dari residual satu pengamatan ke pengamatan yang lain. Model regresi yang baik adalah yang tidak terjadi heteroskedastisitas. (Ghozali, 2011). Hasil dari pengujian heterokedastisitas dapat dilihat pada gambar di bawah ini : 


\section{Gambar 1. Hasil Uji Heteroskedastisitas}

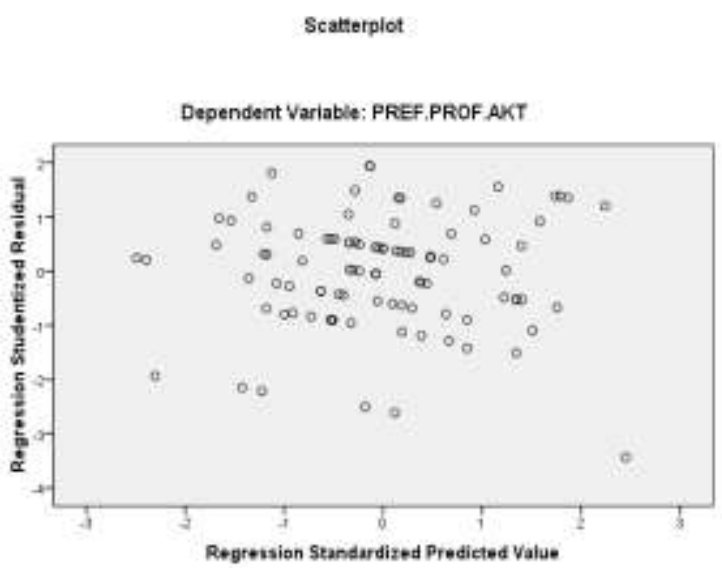

Dengan melihat gambar Scatterplot yang menunjukkan titik-titik yang menyebar diantara titik 0 maka dapat dikatakan tidak terjadi heteroskedastisitas.

\section{Uji Autokorelasi}

Uji ini untuk mengetahui apakah terjadi korelasi pada model di antara kesalahan pengganggu t dengan kesalahan pengganggu pada periode sebelumnya. Dengan sampel (n) 100 ada 4 variabel independen dan menggunakan tingkat signifikansi 5\% maka diperoleh nilai $(\mathrm{Dl})$ yaitu 1,592 dan (du) bernilai 1,758. Hasil dari uji autokorelasi dengan nilai DW 1,992 yang berarti :

- Nilai DW 1,992 lebih besar dari batas atas (du) 1,758

- Nilai DW 1,992 kurang dari 4-1,758 (4-du)

Maka dapat dikatakan bahwa tidak terdapat autokorelasi.

Uji autokorelasi dala model penelitaan ini dapat dilihat pada table berikut ini :

Tabel 6. Hasil Uji Autokorelasi

Model Summary ${ }^{b}$

\begin{tabular}{|c|c|c|c|c|c|}
\hline Model & $\mathrm{R}$ & R Square & $\begin{array}{c}\text { Adjusted R } \\
\text { Square }\end{array}$ & $\begin{array}{c}\text { Std. Error } \\
\text { of the } \\
\text { Estimate }\end{array}$ & $\begin{array}{c}\text { Durbin- } \\
\text { Watson }\end{array}$ \\
\hline 1 & $.309^{\mathrm{a}}$ & .096 & .058 & 2.050 & 1.992 \\
\hline
\end{tabular}

a. Predictors:

(Constant),

SOSIAL,

PROFESIONAL,

PEDAGOGIK,

KEPRIBADIAN

b. Dependent

Variable:

PREF.PROF.AKT

\section{Uji Normalitas}

Hasil uji normalitas dengan menggunakan analisis grafik dapat dilihat pada gambar sebagai berikut : 


\section{Gambar 2. Histogram Uji Normalitas}

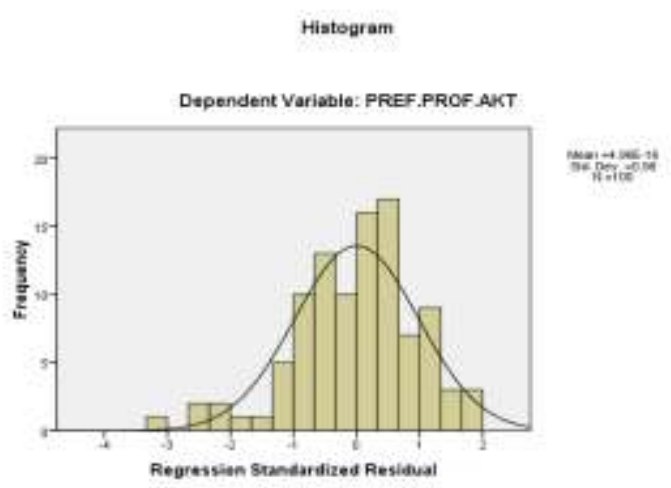

Gambar 3. P-PLOT Uji Normalitas

Normal P.P Plot of Regression Standardized Residual

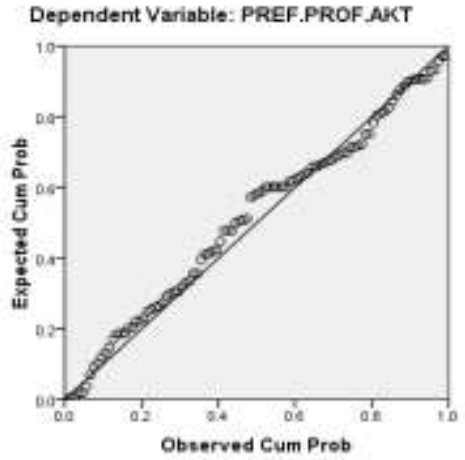

Dari gambar histogram maupun P-Plot dapat dikatakan bahwa variable pengganggu atau residual memiliki distribusi normal, sehingga dapat digunakan dalam model regresi yang akan dilakukan.

\section{Uji Regresi}

Pengujian regresi dilakukan bertujuan untuk mengukur kekuatan hubungan antara dua atau lebih varaibel dan menunjukkan arah hubungan antara variable bebas dan terikat (Ghozali,2011). Model regresi yang digunakan dalam penelitian ini adalah sebagai berikut :

$Y=a_{1}+\beta_{1} X_{1}+\beta_{2} X_{2}+\beta_{3} X_{3}+\beta_{4} X_{4}+\varepsilon$

Keterangan :

Y : Preferensi Profesi Akuntan

$\mathrm{X}_{1}$ : Kompetensi Pedagogik

$\mathrm{X}_{2}$ : Kompetensi Kepribadian

$\mathrm{X}_{3}$ : Kompetensi Profesional

$\mathrm{X}_{4}$ : Kompetensi Sosial

$\beta$ : Koefisien Regresi

$\varepsilon$ : Error

Penelitian ini bertujuan untuk mengetahui pengaruh variable independen (kompetensi pedagogic, kompetensi kepribadian, kompetensi professional dan kompetensi sosial) terhadap varaibel dependen (preferensi profesi akuntan). 
Hasil dari regresi yang dilakukan dapat ditunjukkan sebagai berikut :

Tabel. 7. Hasil Pengujian Regresi Berganda

\begin{tabular}{|l|l|r|r|r|}
\hline \multicolumn{5}{|c|}{ Model Summary } \\
\hline Model & $\mathrm{R}$ & $\begin{array}{c}\mathrm{R} \\
\text { Square }\end{array}$ & $\begin{array}{c}\text { Adjusted } \\
\text { R Square }\end{array}$ & $\begin{array}{r}\text { Std. Error of } \\
\text { the Estimate }\end{array}$ \\
\hline 1 & $.309^{\mathrm{a}}$ & .096 & .058 & 2.050 \\
\hline
\end{tabular}

a. Predictors: (Constant), SOSIAL,

PROFESIONAL, PEDAGOGIK, KEPRIBADIAN

ANOVA $^{\mathbf{b}}$
\begin{tabular}{|l|r|r|r|l|l|} 
Model & \multicolumn{1}{|c|}{$\begin{array}{c}\text { Sum of } \\
\text { Squares }\end{array}$} & df & $\begin{array}{c}\text { Mean } \\
\text { Square }\end{array}$ & F & Sig. \\
\hline 1 Regression & 42.283 & 4 & 10.571 & 2.516 & .046 \\
Residual & 399.157 & 95 & 4.202 & & \\
Total & 441.440 & 99 & & & \\
\hline
\end{tabular}

a. Predictors: (Constant),

SOSIAL, PROFESIONAL,

PEDAGOGIK,

KEPRIBADIAN

b. Dependent

Variable:

PREF.PROF.AKT

Coefficients $^{\mathrm{a}}$

\begin{tabular}{|l|r|r|r|r|r|}
\hline \multirow{2}{*}{ Model } & \multicolumn{2}{|c|}{$\begin{array}{c}\text { Unstandardized } \\
\text { Coefficients }\end{array}$} & $\begin{array}{c}\text { Standardized } \\
\text { Coefficients }\end{array}$ & $\mathrm{t}$ & Sig. \\
\cline { 2 - 6 } & \multicolumn{1}{|c|}{$\mathrm{B}$} & Std. Error & Beta & & \\
\hline 1 (Constant) & 10.391 & 2.431 & & 4.274 & .000 \\
PEDAGOGIK & .156 & .100 & .159 & 1.560 & .122 \\
KEPRIBADIAN & .167 & .104 & .169 & 1.614 & .110 \\
PROFESIONAL & -.137 & .104 & -.136 & -1.311 & .193 \\
SOSIAL & .175 & .136 & .130 & 1.279 & .204 \\
\hline
\end{tabular}

a. Dependent Variable:

PREF.PROF.AKT

Sumber : Data yang diolah, 2016 
Ringkasan dari hasil regresi berganda di atas dapat dilihat di bawah ini :

Tabel 8. Ringkasan Hasil Regresi

\begin{tabular}{|l|l|c|c|}
\hline \multicolumn{1}{|c|}{ Keterangan } & \multicolumn{1}{c|}{ Koefisien } & t test & Sig. \\
\hline Pedagogik & 0,156 & 1,560 & 0,122 \\
\hline Kepribadian & 0,167 & 1,614 & 0,110 \\
\hline Profesional & $-0,137$ & $-1,311$ & 0,193 \\
\hline Sosial & 0,175 & 1,279 & 0,204 \\
\cline { 1 - 2 } F test & 2,516 & & \\
\cline { 1 - 2 } F Sig & 0,046 & \\
\cline { 1 - 2 } $\begin{array}{l}\text { Adjusted } R \\
\text { Square }\end{array}$ & 0,058 & \\
\cline { 1 - 2 } Dependen Variabel : Preferensi Profesi Akuntan \\
\hline
\end{tabular}

Sumber : Data yang diolah, 2016 berikut :

Dengan melihat hasil ringkasan regresi berganda di atas maka di peroleh hasil sebagai

$Y_{1}=10,391+0,156$ Ped $+0,167$ Kep $-0,137$ Prof $+0,175$ Sos $+\varepsilon$

Namun dengan melihat hasil signifikasi yang memiliki nilai semua variable lebih dari 0,05 maka dapat dikatakan bahwa variable independen yang terdiri dari kompetensi pedagogic, kompetensi kepribadian, kompetensi professional dan kompetensi sosial tidak berpengaruh terhadap preferensi profesi akuntan.

\section{PEMBAHASAN}

Penelitian ini ingin mengetahui tentang factor-faktor yang dapat menyebabkan mahasiswa memilih suatu profesi akuntan. Interaksi yang ada di dunia akademis dapat dipertimbangkan sebagai hal yang penting dalam hal ini. Seorang tenaga pengajar (dosen) termasuk ada di lingkungan akademisi.

Dosen sebagai seorang pengajar yang selalu dituntut untuk melakukan perannya secara profesional yaitu dengan hal-hal yang berkaitan dengan kompetensinya. Kompetensi seorang dosen sebagai pengajar menurut UU dosen dan guru dengan tingkat pengukuran dari kompetensi pedagogic, kompetensi kepribadian, kompetensi professional dan kompetensi social. Sehingga penelitian ini menggunakan kompetensi-kompetensi untuk dapat mengukur bahwa kompetensi dosen dapat digunakan untuk mengukur perilaku mahasiswa dalam memilih suatu profesi (akuntansi).

Hasil dari uji yang telah dilakukan dapat diuraikan bahwa hal-hal yang berkaitan dengan kompetensi yang dimiliki dosen yaitu sebagai berikut :

a. Kompetensi pedagogic yang dimiliki dosen tidak dapat digunakan untuk mengetahui minat seorang mahasiswa pada pilihannya terhadap sutau profesi akuntan. Hal ini berarti bahwa kemampuan dosen dalam melakukan pemahaman kepada peserta didik yang dimulai dari merancang, melaksanakan dan mengevaluasi pembelajaran yang bertujuan untuk mengembangkan potensi mahasiswa tidak memiliki pengaruh terhadap pemilihan mahasiswa terhadap suatu profesi akuntan. Meskipun seorang dosen mampu untuk melakukan pemahaman kepada mahasiswa tidak berarti bahwa mahasiswa memilih suatu profesi akuntan.

b. Kompetensi kepribadian yang dimiliki dosen merupakan kemampuan secara pribadi yang merupakan wujudan pribadi yang mantab, stabil, dewasa, arif, berwibawa dan beraklaq mulia, dapat memberikan contoh kepada siswa didik. Ternyata kemampuan dosen dalam hal ini tidak memiliki pengaruh terhadap pemilihan mahasiswa terhadap suatu profesi akuntan. Meskipun seorang dosen mampu membentuk pribadi mahasiswa dengan memberikan contoh kepada mahasiswa tidak berarti bahwa mahasiswa memilih suatu profesi akuntan. 
c. Kompetensi professional seorang dosen dengan ditunjukkan dalam kemampuannya menguasai materi pembelajaran yang luas dan dalam. Penguasaan yang dimaksud adalah penguasaan dalam materi kurikulum untuk pembelajaran dan substansi keilmuannya, didukung dengan penguasaan struktur dan metode keilmuannya. Dengan menguasai suatu materi pembelajaran ternyata dosen tidak dapat menggiring mahasiswa untuk dapat memililih suatu profesi akuntan.

d. Kompetensi social yang dimiliki seorang dosen yaitu kompetensi yang dimiliki untuk dapat berkomunikasi dan bergaul dengan mahasiswa, tenaga kependidikan dan masyarakat secara efektif tidak dapat dijadikan sebagai hal yang menyebabkan mahsiswa memilih profesi akuntan.

Dari penelitian terdahulu Kurnia (2009) tentang profesi akuntan yang diperoleh dari dosen pengajar di kampus. Namun dengan kemampuan dosen berupa kompetensi yang dimiliki dosen tidak dapat diartikan hal tersebut menarik mahasiswa untuk memilih profesi akuntan.

Hal ini juga ada pada penelitian Oding Supriadi (2011) yang menyatakan kemampuan manajerial pembelajaran yang mempengaruhi kualitas pembelajaran akuntansi, dalam penelitian yang dilakukan peneliti bahwa manajerial pembelajaran tidak serta merta dapat membuat mahasiswa memilih profesi akuntan.

Teknik-teknik pembelajaran pada penelitian Filiz Angay Kutluka, Adnan Donmezb, dan Mustafa Gülmezc (2015) termasuk di dalamnya karakteristik dosen pengajar, ternyata dalam penelitian yang dilakukan peneliti tidak dapat menyebabkan mahasiswa memilih profesi akuntan.

\section{KESIMPULAN}

Kesimpulan yang diperoleh dari penelitian adalah bahwa kompetensi yang dimiliki oleh dosen sebagai tenaga pengajar yang terdiri dari kemampuan pedagogic, kompetensi kepribadian, kompetensi professional dan kompetensi social tidak ada kontribusinya terhadap pilihan mahasiswa terhadap suatu profesi akuntan.

\section{SARAN}

Penelitian selanjutnya agar mempertimbangkan pengaruh tidak langsung melalui variable lain dari kompetensi pengajar terhadap preferensi mahasiswa kepada suatu profesi

\section{REFERENSI}

Ernawan, Erni R. 2007."Business Ethics". Penerbit Alfabeta, Bandung.

Ghozali, Imam. 2011. Aplikasi Analisis Multivariate Dengan Program SPSS. Badan Penerbit Universitas Diponegoro.

Hendri, Nedi dan Suyanto. 2014. Faktor-faktor yang mempengaruhi Prilaku Etis Profesi Akuntan Pendidik (Studi Empiris pada PT di Provinsi Lampung. Jurnal AKUISISI, Vol. 10, No. 2, November 2014, hal 21-37.

http://www.bapepam.go.id. diakses tanggal 15 Maret 2015

http://www.bps.go.id. diakses tanggal 15 Maret 2015

http://www.ojk.go.id. Daftar Kantor Akuntan Publik/Akuntan Publik yang Terdaftar Sebagai Auditor Bank di OJK, diakses tanggal 15 Maret 2015.

Kurnia. 2009. "Perbedaan Persepsi Tentang Karier Di Kantor Akuntan Publik Antara Mahasiswa Dan Staf Kantor Akuntan Publik". Ekuitas, Vol. 13, No. 2, Juni 2009, hal 199218.

Kutluka, Filiz Angay *, Adnan Donmezb,Mustafa Gülmezc. 2015. "Opinions Of University Students About Teaching Techniques In Accounting Lessons". Procediing - Social and Behavioral Sciences 191 (2015) $1682-1689$

Samryn, L.M. 2014. "Pengantar Akuntansi" Edisi IFRS. Penerbit Rajagrafindo Persada, Jakarta 
Samsuddina, Mas Ervina *, Noor Sufiawati Khairania, Emelin Abdul Wahida and Fazrul Hanim Abd Sataa. 2015. "Awareness, Motivations and Readiness for Professional Accounting Education: A Case of Accounting Students in UiTM Johor". Procediing Economics and Finance 31 ( 2015 ) $124-133$

Setyawardani, Lydia. 2009. "Persepsi Mahasiswa Senior Dan Junior Terhadap Profesi Akuntan”. Ekuitas, Vol. 13, No. 1, Maret 2009, hal 84-103.

Supriadi, Oding. 2011. "Pengaruh Kapabilitas Manajerial Para Manajer Pendidikan Terhadap Kualitas Pembelajaran”. Jurnal Akuntansi \& Manajemen, Vol. 22, No. 3, Desember 2011, hal 235-246

Sutrisno, Catur Ragil dan Amalia Ilmiani. 2013. "Potensi, Preferensi Dan Perilaku Mahasiswa Terhadap Profesi Auditor". Jurnal Ekonomi Dan Bisnis, Vol. 12 No. 1, Maret 2013, hal 6777.

Undang-Undang Republik Indonesia, No. 14 Tahun 2005, Tentang Guru dan Dosen

Wirianata, Henny dan Sofyan S. Harahap. 2007. "Persepsi Dosen Dan Mahasiswa Akuntansi Terhadap Profesi Akuntan Publik Pasca Enronstudi Kasus Pada Lima PTS Di Jakarta Barat". Media Riset Akuntansi, Auditing dan Informasi, Vol. 7, No. 3, Desember 2007, hal 367-393. 